\title{
History and Current Status of Robotic Totally Endoscopic Coronary Artery Bypass
}

\author{
Jeffrey D. Lee, MD; Mukta Srivastava, MD; Johannes Bonatti, MD
}

\begin{abstract}
Robotic totally endoscopic coronary artery bypass (TECAB) is a minimally invasive endoscopic surgical approach using the daVinci robotic telemanipulation system to perform coronary artery bypass grafting on the arrested or beating heart. It is a procedure that can be a useful alternative to the classic open procedure performed through sternotomy. After extensive modeling in cadavers, the first clinical case was performed in June 1998 placing a left internal thoracic artery graft (LITA) to the left anterior descending artery completely robotically on the arrested heart. During the early and late 2000 s, international groups have adopted this evolving technology, which has included iterations such as beating-heart TECAB, use of bilateral ITA grafting and radial artery grafting, as well as 3- and 4vessel TECAB. TECAB is combined with percutaneous coronary intervention in hybrid procedures. Despite increasing complexity of endoscopic coronary bypass surgery, conversion rates to open bypass surgery have dropped significantly and operative times have decreased. Published major morbidities and mortality rates in arrested- and beating-heart TECAB have been cumulatively in the $0-2 \%$ range and are considered well within the expected range for these highly complex surgical procedures. Long-term survival and freedom from major adverse events also meet the standards of open bypass surgery. (Circ $J$ 2012; 76: 2058-2065)
\end{abstract}

Key Words: Arteriosclerosis; Coronary artery bypass grafting; Coronary artery disease; Ischemic heart disease; Percutaneous coronary intervention

$\mathbf{T}$ otally endoscopic coronary artery bypass (TECAB) is considered by many to be the zenith of minimally invasive surgical approaches to myocardial revascularization. To date, TECAB can only be performed in a reproducible manner using robotic technology. In this procedure, which can be carried out on the beating or arrested heart (off- or onpump), the complete surgical procedure is performed through port incisions using robotic telemanipulation (Figure 1). Robotic coronary artery bypass is technically demanding and requires completion of a learning curve and a careful stepwise approach in order to achieve clinically acceptable results in a reasonable period of time. The main advantages of robotic TECAB are a significant reduction of surgical trauma and preservation of thoracic integrity, more frequent use of double internal thoracic arteries, even in risk groups, and earlier return to normal activities. This review article will survey the literature and detail our own experience and recommendations with this innovative surgical procedure.

\section{History}

\section{Early Development 1998-2000}

The history of robotic coronary artery bypass dates back to 1998 when Stephenson et al reported on the performance of 25 coro- nary anastomoses on isolated porcine hearts placed in a custommade heart holder and thoracic trainer, reproducing the anatomic orientation and rib cage of the human. They anastomosed the harvested right coronary artery (RCA) to the left anterior descending (LAD) coronary artery with the Zeus Robotic Microsurgical System (Computer Motion). After an arteriotomy was made endoscopically in the LAD with robotically controlled scissors, a continuous end-to-side anastomosis was then performed endoscopically with the robotic instruments and a specially designed 6-cm double-armed 7-0 polytetrafluoroethylene suture. All conduits were successfully completed and showed good probe patency. Average time for completion of the anastomosis was $31.7 \pm 2.0 \mathrm{~min} .^{1}$

Ducko et $\mathrm{al}^{2}$ in 1999 reported on calves that were placed on cardiopulmonary bypass (CPB) after the left internal thoracic artery (LITA) was harvested. Subxiphoid endoscopic ports and the Zeus Robotic Microsurgical System (Computer Motion) were used to perform endoscopic coronary artery bypass grafting (CABG) between the LITA and LAD. All anastomoses were successfully completed in a mean time of $33.9 \pm 1.9 \mathrm{~min}$. Angiographic patency was 100\% and confirmed by histology.

Loulmet et $\mathrm{al}^{3}$ in Paris performed the first-in-man robotic TECAB in 2 men in 1998 using the first-generation da Vinci robotic system (Intuitive Surgical, Mountain View, CA, USA).

Received July 30, 2012; accepted July 31, 2012; released online August 11, 2012

Division of Cardiac Surgery, Department of Surgery (J.D.L.), Division of Cardiology, Department of Medicine (M.S.), University of Maryland School of Medicine, Baltimore, MD; and Department of Cardiothoracic Surgery, Cleveland Clinic Abu Dhabi, Abu Dhabi,

United Arab Emirates, Lerner College of Medicine of Case Western Reserve University, Cleveland, OH (J.B.), USA

Mailing address: Jeffrey D. Lee, MD, FACS, University of Maryland Medical Center, Department of Surgery, Division of Cardiac Surgery,

7th Floor 110 South Paca Street, Baltimore, MD 21201, USA. E-mail: jlee@ smail.umaryland.edu

ISSN-1346-9843 doi:10.1253/circj.CJ-12-0981

All rights are reserved to the Japanese Circulation Society. For permissions, please e-mail: cj@j-circ.or.jp 


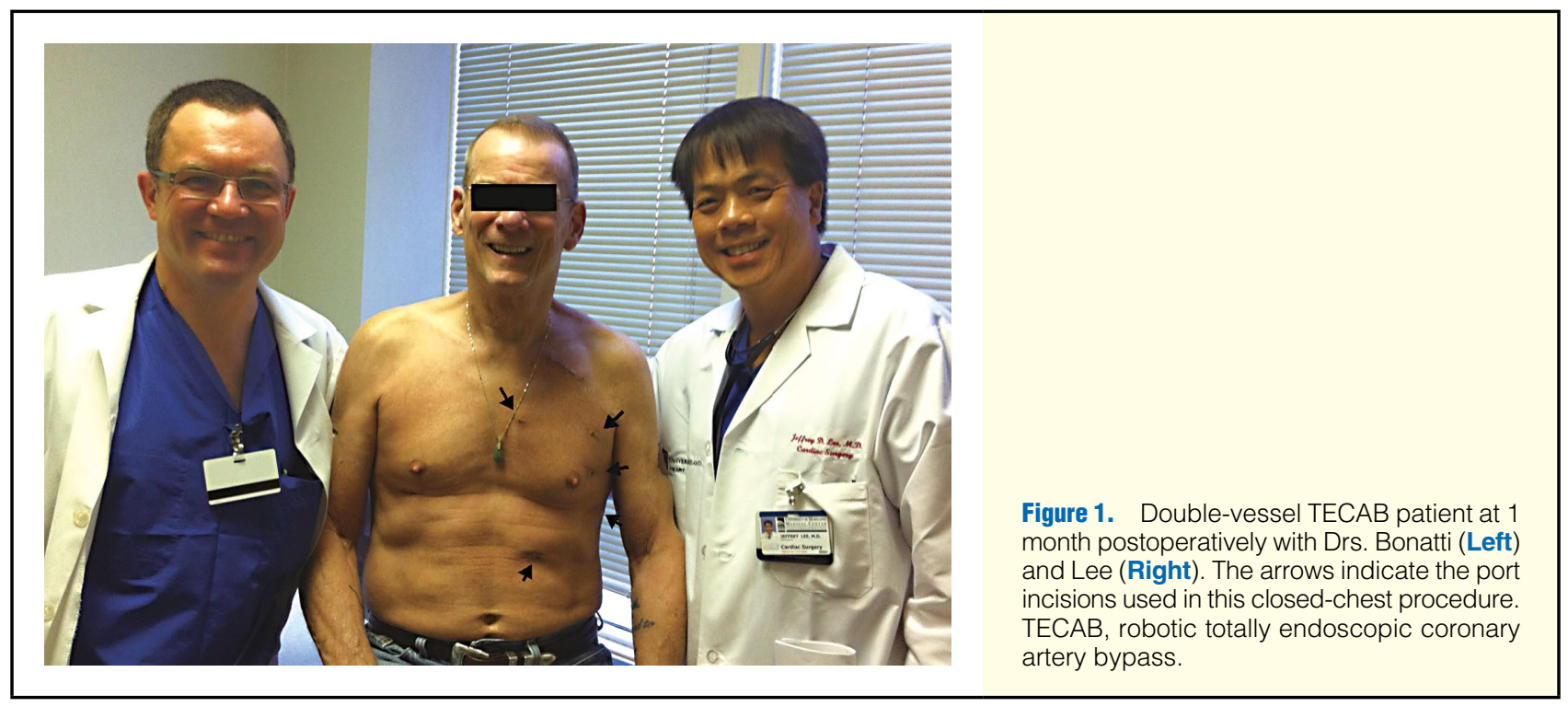

The Heartport system (Heartport, Redwood City, CA, USA) was used for arresting the heart during the anastomosis and the entire operation was completed endoscopically with roboticassisted instruments. Early postoperative coronary angiography (CAG) demonstrated the patency of the grafts in all cases. At 6-month follow-up, all patients were free of symptoms.

In 2000, Damiano et $\mathrm{al}^{4}$ reported on the first US Food and Drug Administration (FDA) trial using the Zeus Robotic Microsurgical System (Computer Motion, Goleta, CA, USA). This system is not produced anymore. It was stipulated by the FDA that only the LITA-LAD anastomosis could be performed robotically. All other anastomoses were to be sewn by hand using a traditional CPB arrested-heart technique: 10 patients were done, 9 via median sternotomy and 1 via left mini-thoracotomy. All the LITA-LAD anastomoses were performed robotically. The total number of grafts performed was $2.3 \pm 0.3$ per patient with a mean cross-clamp time of $51.1 \pm 1.6 \mathrm{~min}$. The time required to perform the LITA-LAD anastomoses with the robotic system was $23.6 \pm 1.4 \mathrm{~min}$ (range $18-30 \mathrm{~min}$ ). All anastomoses were successfully performed and no repair stitches were required. The patient who had a left mini-thoracotomy underwent the procedure utilizing CPB with endoballoon-delivered cardioplegic arrest and a cross-clamp time of $71 \mathrm{~min}$ and anastomotic time of $28 \mathrm{~min}$. Ultrasonic flow measurements of the LITA grafts identified that $8 / 10$ anastomosis were patent with excellent diastolic flow and average flows of $31 \pm 7 \mathrm{ml} / \mathrm{min}$. Two grafts had inadequate flow and were reconstructed manually. In a follow-up report by this same group, their first 18 consecutive patients underwent CAG 6 weeks after the operation and demonstrated $100 \%$ graft patency. At a mean follow-up of $17 \pm 4.2$ months, all patients were NYHA class I and there were no adverse cardiac events. ${ }^{5}$

One of the first multivessel robotic-assisted bypass series using the da Vinci Surgical System (Intuitive Surgical, Mountain View, CA, USA) was reported by Cichon et $\mathrm{al}^{6}$ in Dresden, Germany in 2000. They reported on 17 (4 women, 13 men; median age $63 \pm 7.4$ years) patients with multivessel coronary artery disease (CAD) who were treated using bilateral ITA (BITA). Both arteries were harvested endoscopically using the da Vinci Surgical System and then a 6- to 8-cm mini-thoracotomy in the second intercostal space of the left chest was performed. The ascending aorta was cannulated directly through the chest and venous drainage was achieved percutaneously. The ascending aorta was cross-clamped with a conventional cross-clamp. End-to-side anastomoses were performed between the harvested BITA and the coronary arteries in a standard hand-sewn fashion. Survival was $100 \%$ and operative time was $255 \pm 40.4 \mathrm{~min}$. BITA harvesting took $88.5 \pm 15.9 \mathrm{~min}$ and crossclamp time was $36 \pm 8.7 \mathrm{~min}$. An average of 2.06 anastomoses were performed per patient. One patient $(5.8 \%)$ required reexploration for bleeding. Although not totally endoscopic, this mini-thoracotomy approach was an important evolutionary step towards a completely closed-chest TECAB approach. ${ }^{6}$

Also in 2000, Kappert et $\mathrm{al}^{7}$ from Dresden, Germany reported one of the world's first robotic TECABs using BITA and femoral cannulation with endoballoon-delivered cardioplegic arrest. They placed an in-situ LITA to the OM1 and in-situ right internal thoracic artery graft (RITA) to the LAD. The entire procedure was performed through $31-\mathrm{cm}$ incisions using the da Vinci Surgical System (Intuitive Surgical). Both LITA and RITA were harvested in $102 \mathrm{~min}$ (LITA $48 \mathrm{~min}$, RITA $54 \mathrm{~min}$ ) and cross-clamp time was $98 \mathrm{~min}$. The 2 anastomoses were performed in $48 \mathrm{~min}$ and the entire surgical procedure was completed in $480 \mathrm{~min}$. No complications occurred and the patient was discharged on the 7 th postoperative day. ${ }^{7}$

Finally, in another follow-up report, Damiano et al ${ }^{8}$ reported on 32 patients scheduled for elective primary coronary surgery who underwent endoscopic anastomosis of the LITA to the LAD. Conventional techniques were used to perform the other grafts; 31 patients underwent these procedures via median sternotomy and 1 via an anterior thoracotomy (44 patients were originally placed in the study of which $4(9.1 \%)$ preoperatively and $8(18.2 \%)$ intraoperatively were excluded from analysis due to "unfavorable conditions"). Graft flow averaged $37 \pm 19 \mathrm{ml} / \mathrm{min}$ with anastomotic times of $24 \pm 9 \mathrm{~min}$. Average postoperative length of stay was $5.5 \pm 2.7$ days. There were 3 reoperations for bleeding and CAG at 2 months following the operation revealed overall graft patency of $93 \% .^{8}$

\section{Developments in 2001-2005}

In 2001, Mohr et $\mathrm{al}^{9}$ from Leipzig, Germany, published a large series of 148 patients whom underwent various robotic-assisted cardiac surgical procedures. Using the da Vinci Surgical System (Intuitive Surgical), 131 patients underwent CABG and 
17 patients underwent mitral valve repair. In the $\mathrm{CABG}$ group the system was used in 1 of 3 ways: (1) to take down the ITA followed by a minimally invasive direct coronary artery bypass (MIDCAB-off-pump hand-sewn anastomosis of the LITA to the LAD via a mini-thoracotomy) $(n=81)$; (2) to perform the anastomosis between the ITA and the LAD utilizing sternotomy and CPB $(n=15)$; or (3) for TECAB grafting to robotically anastomose the LITA to the LAD on the arrested $(n=27)$ or beating heart $(n=8)$. In 17 patients with nonischemic mitral valve insufficiency the mitral valve was repaired. Closed-chest CPB with endoballoon-delivered cardioplegic arrest (Port-Access technique; Heartport) was used for arrested-heart TECAB. The ITA was successfully harvested in 79 of 81 patients in the group undergoing $\mathrm{CABG}$ and, after a steep learning curve, was performed in less than $40 \mathrm{~min}$. The postoperative patency rate was $96.3 \%$. TECAB was completed in 22 of 27 cases with $95.4 \%$ patency as demonstrated by CAG at 3-month followup. On the beating heart, closed-chest endoscopic bypass grafting was successfully performed in only 2 of 8 patients with the use of an endoscopic stabilizer. Overall early and late mortality in this cohort of 148 patients was $2.0 \% .^{9}$

Kappert et $\mathrm{al}^{10}$ also reported in 2001 on 37 patients ( 5 females, 32 males, median age $62 \pm 9$ years) who underwent beating-heart TECAB. Using the da Vinci Surgical System (Intuitive Surgical), ITA harvesting and anastomoses on a beating heart were able to be completed in $29(78 \%$ ) patients (4 females, 25 males, median age $64 \pm 9.8$ years) with $100 \%$ survival.

Dogan et $\mathrm{al}^{11}$ in Frankfurt reported in 2002 on their experience with 45 consecutive patients undergoing robotic singleor double-vessel coronary artery bypass. In 37 patients, a LITA to LAD or RITA to RCA was performed. In 8 patients, double-vessel bypass procedures were performed. Of the initial 20 coronary cases that were started with a closed-chest approach, $10(50 \%)$ required conversion to either left-sided mini-thoracotomy $(n=7)$ or median sternotomy $(n=3)$. Four of these conversions occurred during double bypass procedures. The reasons for conversion were intraoperative bleeding from the anastomotic site $(n=2)$, cross-clamp time $>2 h(n=4)$, injury to the ITA graft $(n=1)$, and contraindication to advancement of the Port-Access EndoClamp device $(n=3)$. In the last 20 patients of this series, only 1 conversion to mini-thoracotomy (5\%) was required. ${ }^{11}$

In 2003, Novick et $\mathrm{al}^{12}$ of London, Ontario, analyzed their learning curve for beating-heart robotic CABG. With an overall experience of 90 cases, they found that operating time was reduced from a mean of $537 \pm 119 \mathrm{~min}$ in the first quintile to $307 \pm 56 \mathrm{~min}$ in the last quintile. Incidences of occluded and wrong vessel grafted decreased with increasing experience: $28 \%, 1^{\text {st }}$ quintile; $6 \%, 2^{\text {nd }}$ quintile; $11 \%, 3^{\text {rd }}$ quintile; $17 \%, 4^{\text {th }}$ quintile; $11 \%, 5^{\text {th }}$ quintile. They recommended that $18-20$ cases be considered the steepest part of the learning curve. ${ }^{12}$

Our group reported on our initial learning curve in Innsbruck, Austria, with our first 50 robotic procedures. After baseline training, procedure modules were introduced in a stepwise manner: robotically assisted LITA harvesting and completion of the procedure as conventional CABG, MIDCAB, or off-pump coronary artery bypass $(\mathrm{OPCAB})(\mathrm{n}=19)$, robotically assisted suturing of LITA to LAD during conventional CABG $(n=15)$, then finally TECAB on the arrested heart using remote-access perfusion and aortic endocclusion $(n=15)$. In this series, 1 patient was excluded intraoperatively because of pleural adhesions. A significant learning curve was observed for LITA harvesting time $(\mathrm{P}<0.001)$, and total operative time $(\mathrm{P}=0.028)$. The conversion rate with TECAB was $2 / 15(13 \%)$. Intensive care unit (ICU) stay correlated significantly with total opera- tive time ( $\mathrm{r}=0.427, \mathrm{P}=0.002)$ and there were no hospital mortalities. We concluded and currently recommend that TECAB be implemented into a cardiac surgical program using a similar stepwise modular approach. ${ }^{13}$

In 2005, we reported on our initial series of 107 cases of robotic endoscopic CABG. From June 2001 to March 2005, robotically assisted CABG using the daVinci surgical system (Intuitive Surgical) was carried out in patients with single- and multivessel CAD. Robotically assisted LITA harvesting was performed on all patients with completion of the procedure as conventional CABG, MIDCAB, or OPCAB $(n=22)$, robotically assisted suturing of LITA to LAD during conventional CABG ( $n=28)$, TECAB on the arrested heart using remote-access perfusion $(n=48)$, TECAB on the beating heart using an endostabilizer $(n=8)$, and a takedown of adhesions (TECAB intended) $(n=1)$. Hospital mortality was zero. Undesirable surgical events (USE) such as conversion to sternotomy, on table or postoperative revision of the anastomosis occurred in 34 of $107(32 \%)$ patients. Median ventilation time and ICU stay were 11 (0-278) and 21(11-389) hours, respectively. Cumulative 3 -year survival was $100 \%$ and freedom from angina at 3 years was $97 \% .^{14}$

\section{Developments in 2006-2010}

In 2006, we discussed some of the technical challenges to robotic TECAB. From October 2001 through October 2004, 40 patients received robotically assisted totally endoscopic LITA to LAD grafting with the da Vinci telemanipulation system (Intuitive Surgical). All patients underwent remote-access CPB and anastomoses were performed on the arrested heart. Undesirable technical events of various grades occurred in $20(50 \%)$ of 40 patients: bleeding from a port hole in $3(8 \%)$, LITA damage in $3(8 \%)$, epicardial lesions in $3(8 \%)$, remote-access perfusion problems in $9(23 \%)$, bleeding from the anastomosis in $4(10 \%)$, and anastomotic stenosis in $2(5 \%)$. There were no hospital mortalities. Between patients without technical difficulties (group 1) and those in whom problems occurred (group 2): there were significant differences in total operative time of $314 \mathrm{~min}$ (260-540 min) vs. $418 \mathrm{~min}(270-690 \mathrm{~min}$; $\mathrm{P}=0.007)$, ventilation time of $6 \mathrm{~h}(0-26 \mathrm{~h})$ vs. $14 \mathrm{~h}(0-278 \mathrm{~h} ; \mathrm{P}=0.004)$, ICU stay of $20 \mathrm{~h}(11-70 \mathrm{~h})$ vs. $44 \mathrm{~h}(16-336 \mathrm{~h} ; \mathrm{P}=0.183)$, hospital stay of 7 days (4-13 days) vs. 8 days (5-21 days; $\mathrm{P}=0.038)$, and cumulative freedom from angina at 36 months of $93 \%$ vs. $100 \%(\mathrm{P}=0.317)$. We concluded that technical difficulties during TECAB can translate into prolonged operative and ventilation times and prolonged hospital stay. Short-term survival and freedom from angina, however, did not appear to be compromised. ${ }^{15}$

Also in 2006, Srivastava et al in Odessa, Texas, reported on 150 patients who underwent CABG through small lateral thoracotomies using robotic assistance for harvesting of BITA. After both ITAs were harvested, a small anterolateral thoracotomy was done, enlarging the camera port incision. Distal anastomoses were performed on a beating heart using nitinol surgical clips. Intercostal cryoanalgesia and local anesthetic infusion were used for pain management. Planned arterial revascularization was completed in 148 patients. The mean number of arterial grafts per patient was $2.6 \pm 0.8$. All coronary arteries could be reached with BITA as in-situ or composite grafts. There were no mortalities, strokes, myocardial infarctions, or wound infections. Seven patients had new onset atrial fibrillation. Four patients required exploration for postoperative bleeding. The mean postoperative length of stay was 3.6 \pm 2.9 days. Again, although not totally endoscopic, this minithoracotomy robotic-assisted $\mathrm{CABG}$ approach was another 
important evolutionary step towards a completely closed-chest TECAB approach. ${ }^{16}$

In 2006, the FDA-sanctioned multicenter trial on the safety and efficacy of the da Vinci Surgical System (Intuitive Surgical) for TECAB was reported. Patients requiring LAD revascularization were eligible. The procedure was performed with femoral-femoral CPB, endoaortic balloon occlusion, and thoracoscopy. All aspects of the procedure were performed with the robotic system, from ITA harvesting to intracorporeal coronary anastomosis. In total, 98 patients requiring single-vessel LAD revascularization were enrolled at 12 centers; 13 patients $(13 \%)$ were excluded intraoperatively (eg, failed femoral cannulation, inadequate working space). In the 85 patients (69 men, age $58 \pm 10$ years) who completed TECAB, CPB time was $117 \pm 44 \mathrm{~min}$, cross-clamp time was $71 \pm 26 \mathrm{~min}$, and hospital length of stay was $5.1 \pm 3.4$ days. There were $5(6 \%)$ conversions to open techniques. There were no strokes or deaths, 1 early reintervention, and 1 myocardial infarction (1.5\%). Threemonth CAG was performed in 76 patients, revealing significant anastomotic stenoses $(>50 \%)$ or occlusions in 6 patients. Overall freedom from reintervention or angiographic failure was $91 \%$. Accordingly, in this important multicenter trial, robotic TECAB was accomplished with no mortality, low morbidity, and angiographic patency and reintervention rates comparable with published open surgical data. ${ }^{17}$

Our group in 2007 reported on a series of double ITA TECAB cases. ${ }^{18}$ From 2004 to 2006, 10 patients underwent endoscopic placement of the RITA to the LAD in combination with LITA grafting to an obtuse marginal (OM). Indications for the operation were isolated left main disease or left main equivalents. All procedures were performed using the da Vinci telemanipulation system, remote-access perfusion, and aortic balloon endo-occlusion; 7 of the 10 interventions were completed endoscopically, and 3 patients were converted to sternotomy. RITA harvesting time was 40 min (range, 29-49 min); LITA harvesting time was $38 \mathrm{~min}$ (range, 29-48 $\mathrm{min}$ ). LAD and OM anastomotic times were $23 \mathrm{~min}$ (range, $14-53 \mathrm{~min}$ ) and $38 \mathrm{~min}$ (range, 29-48 min), respectively. Total TECAB time was $477 \mathrm{~min}$ (range, 385-545 min). Median ventilation time was $15 \mathrm{~h}$ (range, 6-40h), median ICU stay was $41 \mathrm{~h}$ (range, 15$141 \mathrm{~h}$ ), and patients were discharged after a median of 7 days (range, 5-22 days). No major adverse cardiac or cerebrovascular events occurred during follow-up. ${ }^{18}$

Results from a multicenter European study were published in 2007. ${ }^{19}$ Between September 1998 and November 2002, a total of 228 patients with CAD were scheduled for TECAB with the da Vinci Surgical System (Intuitive Surgical) at 5 European institutions. Patients underwent TECAB with either an on-pump (group A, n=117) or an off-pump approach (group $\mathrm{B}, \mathrm{n}=111$ ) and were followed up for 6 months. Procedural feasibility was demonstrated through the completion of 164 successful totally endoscopic cases; 64 patients (group C, 28\%) had conversion to non-robotic procedures. Overall procedural efficacy, as defined by angiographic patency or lack of ischemic signs on stress electrocardiography, was $97 \%$. The incidence of major adverse cardiac events within 6 months was $5 \%$. Graft patency and major adverse cardiac events for both approaches were comparable to those reported in the Society of Thoracic Surgeons database.

Kappert et $\mathrm{al}^{20}$ reported in 2008 on their first 5-year followup of patients after TECAB in a single institution. From May 1999 to June 2001, 41 patients (36 males, 5 females; mean age, $60.6 \pm 8.9$ years) underwent beating-heart TECAB for isolated high-grade lesions of the LAD by means of the da Vinci Surgical System (Intuitive Surgical). Clinical follow-up was per- formed 5 years later. Endpoints for follow-up were freedom from major adverse events such as death, myocardial infarction, and repeat revascularization of the LAD. Hospital survival was $100 \%$. Overall survival after 5 years was $92.7 \%$ (38/41 patients); 3 (7.3\%) patients died of noncardiac causes. Freedom from reintervention on the LAD after a mean of $69 \pm$ 7.4 months was $87.2 \%$ (36/41 patients). Freedom from any major adverse events during the follow-up period was $75.7 \%$ (31/41 patients). In this beating-heart TECAB series, they concluded that the need for reintervention of the target vessel left room for improvement and may be considered reflective of early experience with a new surgical technique. ${ }^{20}$

Our group at Innsbruck Medical University then addressed the issues of quality of life (QOL) after robotic TECAB. QOL evaluations were performed before the operation and at 1, 3 and 6 months after the procedure using the SF-36 health survey and a standardized questionnaire. At 3 months, TECAB patients showed significantly better QOL scores related to bodily pain and physical health. Hospital stay and time to restoration of daily activities were significantly shorter in TECAB patients. Patients converted to sternotomy experienced similar courses to standard sternotomy patients in terms of QOL. ${ }^{21}$

Srivastava et al reported in 2009 on 214 patients in Odessa, Texas, who underwent successful beating-heart TECAB from July 2004 to June 2007. Single-, double-, and triple-vessel beating-heart TECAB was performed in 139, 68, and 7 patients, respectively; 50 patients underwent a planned hybrid revascularization and $80 \%$ of patients (172 of 214) underwent computed tomography angiography (CTA) or conventional angiography within 3 months of surgery. On CTA, the analysis included gross patency, stenosis within the graft, and contrast in the grafted coronary artery. A FitzGibbon score was used to analyze graft patency and anastomotic quality in patients undergoing conventional angiography. Clinical follow-up was done in all patients for any major adverse cardiac event. There were no myocardial infarctions, operative mortalities, or conversions to CPB. All patients who had CTA had grossly patent grafts without stenosis and demonstrated opacification of the grafted coronary artery. In total, 57 grafts were studied in 39 patients by conventional angiography postoperatively during hybrid revascularization. At the time of study, all grafts except 1 had FitzGibbon grade A anastomosis and TIMI 3 flow; 3 patients $(1.4 \%)$ required reintervention at 2,3 , and 13 months after initial beating-heart TECAB, with a clinical freedom from graft failure of $98.6 \% .^{22}$

\section{Developments Since 2011}

The importance of the institutional learning curve was exhibited by a subsequent report in 2012 detailing the operative results of the same surgeon working in a new institution. A retrospective clinical review of 106 patients undergoing beating-heart TECAB (72\% multivessel) at the University of Chicago was performed. Of the 106 patients, $1 \%$ underwent quadruple TECAB, $8 \%$ triple, $63 \%$ double, and $28 \%$ single. The emergency conversion rate for hemodynamic instability was $6.6 \%$. The postoperative renal failure rate (doubling of baseline serum creatinine or dialysis required) was $7.5 \%$. Overall, 23 patients $(21.7 \%)$ exhibited at least 1 major morbidity/mortality (4 deaths). The number of vessels bypassed (single/double/triple/ quadruple) correlated positively with the surgical operating room time, the lung separation time, vasoactive medication use, blood use, postoperative ventilation time $>24 \mathrm{~h}$, ICU length of stay, and hospital length of stay. Increased surgical time was significantly associated with morbidity $(\mathrm{P}=0.011)$ and mortality $(\mathrm{P}=0.043)$. A comparison with the Society for Thoracic 


\begin{tabular}{|c|c|c|c|c|c|c|c|}
\hline Author and reference & Cases & Conversion & $\begin{array}{l}\text { Perioperative } \\
\text { mortality }\end{array}$ & $\begin{array}{l}\text { Revision for } \\
\text { bleeding }\end{array}$ & Stroke & Renal failure & $\begin{array}{l}\text { Length of } \\
\text { stay, days }\end{array}$ \\
\hline Loulmet et $\mathrm{al}^{3}$ & 2 & 1 & 0 & & & & 6.5 (mean) \\
\hline Dogan et al ${ }^{11}$ & 38 & 7 & 0 & 2 & 1 & & $8.6 \pm 2.7$ \\
\hline Bonatti et al ${ }^{15}$ & 40 & 9 & 0 & 7 & 0 & 0 & 7.5 \\
\hline Argenziano et al ${ }^{17}$ & 98 & 5 & 0 & 3 & 0 & 1 & $5.1 \pm 3.4$ \\
\hline de Canniere et al ${ }^{19}$ & 90 & 27 & 0 & & & & \\
\hline Bonatti et al ${ }^{34}$ & 100 & 11 & 0 & 8 & 1 & 0 & 6 \\
\hline Bonatti et al ${ }^{26}$ & 161 & 23 & 0 & 10 & 3 & 1 & $6(4-22)$ \\
\hline Total, n (\%) & 529 & $83 / 529(15.6)$ & 0/529 (0.0) & $30 / 437(6.8)$ & $5 / 437(1.1)$ & 2/399 (0.5) & \\
\hline
\end{tabular}

TECAB, robotic totally endoscopic coronary artery bypass.

\begin{tabular}{|c|c|c|c|c|c|c|c|}
\hline Author and reference & Cases & Conversion & $\begin{array}{c}\text { Perioperative } \\
\text { mortality }\end{array}$ & $\begin{array}{c}\text { Revision for } \\
\text { bleeding }\end{array}$ & Stroke & Renal failure & $\begin{array}{l}\text { Length of } \\
\text { stay, days }\end{array}$ \\
\hline de Canniere et al ${ }^{19}$ & 117 & 37 & 2 & & & & \\
\hline Kappert et al ${ }^{35}$ & 3 & 0 & 0 & & & & $6 \pm 1$ \\
\hline Boyd et $\mathrm{a}^{36}$ & 6 & 0 & 0 & & & & $8.6 \pm 2.7$ \\
\hline Loisance et $\mathrm{al}^{37}$ & 13 & 11 & 1 & & & & \\
\hline Srivastava et al ${ }^{38}$ & 108 & 15 & 0 & $1 / 93$ & 0 & $1 / 93$ & $3.4 \pm 2.0$ \\
\hline Srivastava et al ${ }^{22}$ & 241 & 27 & 0 & 2 & 1 & 1 & \\
\hline Jegaden et $\mathrm{al}^{39}$ & 78 & 19 & $1 / 59(1.7)$ & $5 / 59(8.5)$ & $0 / 59(0.0)$ & & $5.5 \pm 1.6$ \\
\hline Gao et $\mathrm{al}^{40}$ & 60 & 2 & 0 & 1 & 0 & 0 & $5.0 \pm 1.5$ \\
\hline Dhawan et $\mathrm{al}^{23}$ & 106 & 4 & 4 & 4 & 2 & 8 & $5.2(2-24)$ \\
\hline Balkhy et al ${ }^{25}$ & 120 & 3 & 1 & 2 & 1 & 0 & $3.3 \pm 2.4$ \\
\hline Total, n (\%) & 852 & $118 / 852(13.8)$ & $9 / 852(1.0)$ & $15 / 679$ (2.2) & 4/679 (0.58) & $10 / 620(1.6)$ & \\
\hline
\end{tabular}

TECAB, robotic totally endoscopic coronary artery bypass.

Surgeons expected outcomes revealed a similar hospital length of stay but an increased incidence of prolonged ventilation $(\mathrm{P}=0.003)$, renal failure $(\mathrm{P}<0.001)$, morbidity $(\mathrm{P}=0.045)$, and mortality $(\mathrm{P}=0.049)$. Because the same surgeon had published in 2009 excellent clinical results with the same procedure, an institutional learning curve may be an important contributing factor to these results. ${ }^{23}$

Recent developments include the increased use of automated anastomotic connector devices in TECAB. Matschke et $\mathrm{al}^{24}$ performed a US multicenter trial in 2005 using a novel distal connecting device, the C-Port System (Cardica, Redwood City, CA, USA). Five centers enrolled 133 patients in open cases performed through sternotomy. Outcome variables were intraoperative device performance, incidence of device-related adverse events, predischarge and 6-month angiographic graft patency, and 12-month clinical outcome. Independent core laboratories performed qualitative and quantitative angiographic and computed tomographic assessments. The C-Port was used to perform a vein-to-coronary anastomosis in 130 patients with conversion to a hand-sewn anastomosis necessary in 11 patients because of inadequate target site preparation, inappropriate target vessel selection, or both. Inadequate blood flow related to poor runoff required conversion in 3 additional patients. Three patients died before discharge of causes unrelated to the device. At discharge, 113 patients had a C-Port implant in place, and 104 C-Port anastomoses were studied by means of angiography, resulting in 100 FitzGibbon A, 3 FitzGibbon B, and 1 FitzGibbon 0 classifications. At 6 months, another patient had died of a device-unrelated cause, and 98 patients were evaluated by CAG $(n=89)$. Overall patency
(FitzGibbon A) was 92.1\%; 3 C-Port anastomoses were rated FitzGibbon B, and 4 were rated FitzGibbon 0. At 12 months, $107(98.2 \%)$ of 109 alive patients were followed up and had no device-related major adverse cardiac events. ${ }^{24}$

In 2011, Balkhy et $\mathrm{al}^{25}$ reported on their results with this distal connecting device in a flexible version specifically designed for TECAB. From January 2008 to April 2010, 120 patients (age range, 43-86 years, 72\% male) underwent either single- or multivessel all-arterial, TECAB using the da Vinci Surgical System (Intuitive Surgical) and the Flex A distal anastomotic connecting device (Cardica). Patients with multivessel disease involving branches of the right coronary and circumflex arteries underwent hybrid revascularization with stents. Eighty-five ITA grafts in 68 patients were evaluated at a mean of 4 months using multidetector computed tomography and angiography (in 18 hybrid patients). Mean hospital stay was $3.3 \pm 2.4$ days. There was 1 postoperative death (the same patient had a stroke secondary to carotid disease), and 1 postoperative myocardial infarction. Two patients were converted to a mini-thoracotomy and 1 patient was converted to sternotomy. One patient required CPB support through femoral cannulation. Mean intraoperative transit time flow in all the ITA grafts was $76 \pm 43 \mathrm{ml} / \mathrm{min}$ and the pulsatility index was $1.5 \pm 0.5$. Of the 85 grafts evaluated angiographically, 80 were patent at a mean of 4 months $(94.1 \%) .^{25}$

Our team recently reported on our experience with multivessel TECAB from 2001 to 2011: 196 patients aged 62 years (range, 38-86 years), male $(78.6 \%)$, ejection fraction $55 \%$ (range, 15-80\%), EuroSCORE 2 (range, 0-12) underwent double- $(87.7 \%)$, triple- $(11.7 \%)$, or quadruple- $(0.5 \%)$ vessel 
TECAB. Median operative time was 367 (168-865) min, with a conversion rate of $17.3 \%$, revision for bleeding of $4.6 \%$, stroke $1 \%$, and mortality of $2 \%$. Long-term survival and freedom from major adverse cardiac and cerebral events at 5 years were $96 \%$ and $73 \%$, respectively. ${ }^{26}$

Concerning overall historic development, it can be stated that major steps were taken during the first 14 years of TECAB application. Hardware has significantly improved since a third generation of robotic telemanipulators has become available. A fourth robotic arm and the introduction of procedure-specific instrumentation, such as a robotic endostabilizer, have allowed complex endoscopic procedures such as triple and quadruple CABG both on the arrested (Table 1) and the beating heart (Table 2). At several centers TECAB is combined with percutaneous coronary intervention (PCI) in hybrid operations. Complex combinations of multivessel TECAB and multivessel PCI are now being carried out routinely. Hybrid interventions are also being conducted simultaneously in hybrid operating rooms. TECAB has reached a highly reproducible stage at dedicated centers.

\section{Indications and Contraindications}

It is our opinion that in experienced centers, all patients with focal ischemic CAD should be considered for robotic TECAB either as sole therapy or as a component of hybrid revascularization. Those with more diffuse disease requiring more than 3 vessels to revascularize may be better served by more traditional open revascularization approaches.

Proper patient selection is of utmost importance. In general, lower risk patients should be chosen during the learning curve period as these patients may more likely tolerate prolonged operative times and technical errors. Patients in cardiogenic shock and multisystem organ failure are contraindicated for this type of surgery. Redo operations can be performed but are technically challenging and should be the rare exception rather than the rule.

As prolonged periods of single-lung ventilation are necessary during TECAB, patients with severely impaired pulmonary function should be excluded. We evaluated the effect of pulmonary function testing on outcomes in TECAB in 174 consecutive TECAB patients at the University of Maryland; 16 of $174(9.2 \%)$ patients required conversion to sternotomy. Those requiring conversion had significantly lower forced vital capacity and forced expiratory volume in $1 \mathrm{~s}$ (FVC: 3.1L [range, 1.4-4.6L] vs. 3.6L [1.3-7.1L] [P=0.021]; FEV1: 2.2L [1.3$3.5 \mathrm{~L}]$ vs. $2.6 \mathrm{~L}[0.9-4.9 \mathrm{~L}][\mathrm{P}=0.041])$. Interestingly, parameters such as FVC \% predicted, FEV1\% predicted, FEV1/FVC ratio, and DLCO $\%$ predicted had little effect on clinical outcome. These findings appear to suggest that limitations in intrathoracic space are important determinants of technical success in this closed-chest procedure. Similarly, in patients with enlarged hearts that almost reach the lateral thoracic rib cage, we have found that prolonged anastomotic, CPB, and operative times should be expected. Based on the preoperative CTA, having less than $25 \mathrm{~mm}$ from the lateral heart border to the adjacent rib led to longer operative times (242 [range, 123-605] vs. 225 [112-390] min, $\mathrm{P}=0.06)$, longer ICU stay (47 [15-339] vs. 24 [15-161] h, $\mathrm{P}=0.001$ ), and longer hospital stay $(6[3-18]$ vs. 5 [3-11] days, $\mathrm{P}=0.001)$.

Preoperative low EF, ${ }^{27}$ presence of an intraaortic balloon pump, ${ }^{28}$ being morbidly obese ${ }^{29}$ or having positive HIV status $^{30}$ are not absolute contraindications to TECAB.

As with any type of CABG surgery, generalized diffuse atherosclerosis should be a warning sign. We perform contrast enhanced CTA of the entire vascular system on all TECAB
Table 3. Preoperative Testing for TECAB

Complete history and physical

CT angiogram of chest, abdomen, pelvis

Upper extremity arterial duplex scanning

Carotid duplex scanning

Pulmonary function testing

CT, computed tomography; TECAB, robotic totally endoscopic coronary artery bypass.

candidates. We have found that those patients with greater degrees of atherosclerosis have longer operative and ventilation times and prolonged hospital stay. Multi-morbid patients should be tackled carefully by experienced TECAB surgeons and should definitely be avoided during the learning curve.

Concerning preoperative testing of TECAB patients, the principles of open CABG surgery should be followed, but additional examinations are necessary for adequate procedure planning. Most importantly, CTA of the chest, abdomen and pelvis gives information about the size and position of the heart, intramyocardial course of the coronary target vessels, any structural abnormalities of the lungs, and the grade of generalized atherosclerosis. Our TECAB preoperative protocol is shown in Table 3.

\section{Surgical Technique}

The general setup of the patient in our hybrid operating room is shown in Figure 2. After standard induction of anesthesia, patients undergo double-lumen intubation or placement of a bronchial blocker for single-lung ventilation. Both radial arteries are cannulated for invasive monitoring of the endoaortic occlusion catheter. A transesophageal echocardiography (TEE) probe is routinely inserted to assess cardiac function and to place and monitor the Port-Access system. In addition, a pulmonary artery vent catheter is inserted percutaneously through the right internal jugular vein. The patient is placed supine on the operating room table and a small roll is placed below the level of the tip of the left scapula to allow the shoulder to roll backwards to avoid conflict with the right-sided robotic arm. Both arms are tucked at the patient's side, although the left elbow is kept bent to allow better access to the left thorax. Near-infrared spectroscopy (NIRS) sensing pads are placed on both legs to continually monitor distal leg perfusion. The patient is prepped and draped and left lung is collapsed, and a camera port is inserted into the fifth intercostal space in the anterior axillary line. $\mathrm{CO}_{2}$ is insufflated up to $10 \mathrm{~cm} \mathrm{H}_{2} \mathrm{O}$ pressure. Additional ports are placed in the third and seventh intercostal spaces between the anterior axillary and mid-clavicular lines and then robotic ITA harvesting is carried out in a skeletonized fashion with the cautery set at $15 \mathrm{~W}$. In parallel with ITA harvesting, the groin vessels are exposed.

\section{Arrested-Heart Technique}

After heparinization, a venous drainage cannula is positioned in the right atrium, and an arterial perfusion cannula with a side arm for the endoballoon is advanced into the femoral artery using the Seldinger technique. Both cannulas are then connected to the heart-lung machine. A distal perfusion catheter for the distal leg is also installed. Through the arterial cannula's side arm, the aortic endo-occlusion balloon is advanced into the ascending aorta under TEE guidance. The pericardial fat pad is then removed and the pericardium is opened in an 


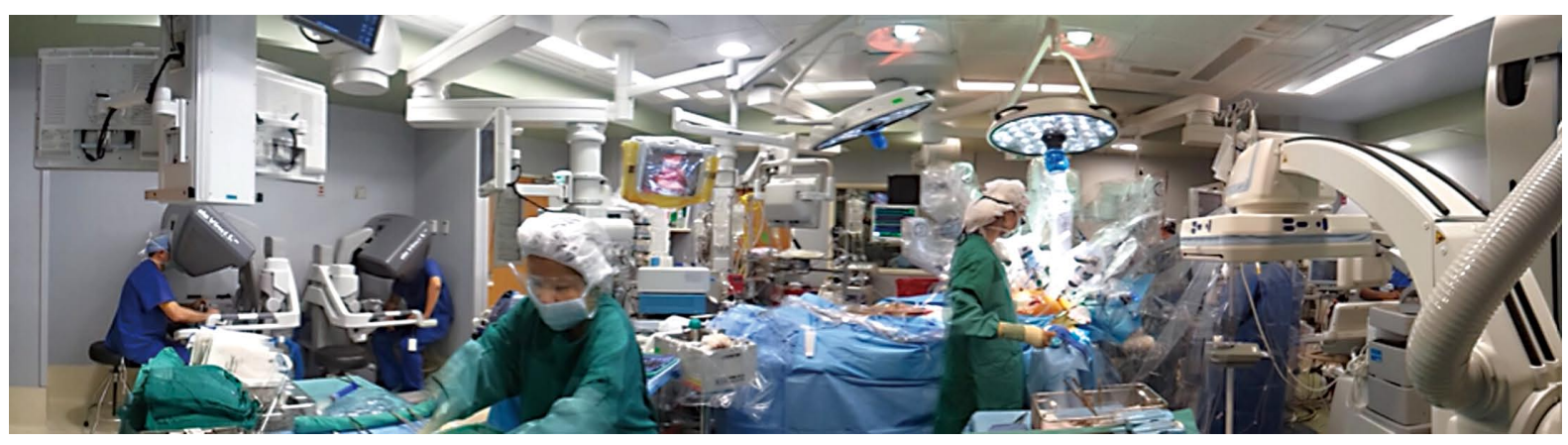

Figure 2. TECAB procedure being performed in the University of Maryland hybrid operating room. TECAB, robotic totally endoscopic coronary artery bypass.

L-shaped fashion and target vessel(s) identified. The free flow of the ITA is checked. The heart-lung machine is started and the endo-aortic occlusion balloon is inflated just above the sinotubular junction under TEE control. Periodic infusions of adenosine and blood cardioplegia are given to arrest the heart and repeated every $20 \mathrm{~min}$. Under cardioplegic arrest, the target vessel is dissected and incised. Silastic tapes may be used to control blood flow in the target vessel if necessary. End-toside anastomoses are then carried out robotically between the LITA and/or RITA and the target vessel(s) using a doublearmed 7-cm, 7-0 pronova suture. The endoaortic occlusion balloon is then deflated. During reperfusion, hemostasis is carried out in the ITA beds and pericardium. Then the patient is weaned from CPB, decannulated and protamine given. The groin vessels are reconstructed and the distal perfusion catheter removed. A chest tube is inserted through the camera port and tunneled to the lower instrument port where it is fixed. All ports are closed in layers as the well as the groin incision. We have performed up to 4 distal anastomosis with this technique. ${ }^{31,32}$

\section{Beating-Heart Technique}

For those patients deemed to be at too high a risk for an arrested-heart TECAB (ie, patients with severe generalized atherosclerosis), beating-heart TECAB may be performed. The patient is prepped and draped in the same manner as for arrested-heart TECAB. All steps up to target vessel dissection are the same including cannulation, in this case, prophylactically. We preferentially perform left axillary cannulation in these patients to avoid the possibility of retrograde arterial perfusion. A subxiphoid port for the Endo stabilizer is placed and the target vessel is stabilized. Silastic snares provide temporary proximal control during target vessel arteriotomy and placement of an intraluminal shunt. End-to-side anastomoses are then carried out using a double-armed 7-cm, 7-0 pronova suture in a running fashion. Before completion of the anastomosis, the shunt is removed.

\section{Current Results}

Results according to our literature review are displayed in Tables 2,3 for arrested- and beating-heart TECAB respectively. The overall reported mortality $(0 \%$ for arrested-heart TECAB , $1.0 \%$ for beating-heart TECAB) and morbidity are very favorable, despite application of these innovative techniques and surgeon-, team-, and institution-specific learning curves. A clear trend in declining conversion rates over the years can be seen. Long-term graft patency was recently reported by investigators in London, Ontario. In that report, 82 patients following robotic-assisted $\mathrm{CABG}$ were followed with graft patency assessments using cardiac catheterization or CTA or both, and stress myocardial perfusion scintigraphy for a mean follow-up of 8 years \pm 16.3 months. The patency rate of all robotic-assisted CABG grafts was $92.7 \%$ with the patency rate of LITA to the LAD of $93.4 \% .{ }^{33}$

\section{Conclusion}

Over the span of approximately 14 years (1998-2012), robotic TECAB has evolved from experimental work in animals and cadavers to 3- and 4-vessel TECABs performed in humans. A third generation of robotic devices is now available, which allows complex multivessel procedures to be performed routinely on both the arrested and beating heart. According to current data, TECAB appears safe and effective. Learning curves are a fact and need to be taken into consideration as new programs are initiated. Conversion to open CABG has to be accepted as an alternative option in cases of technical difficulties. Conversion rates and operative times decrease with experience. This procedure is certainly here to stay, but will probably still be primarily performed by committed teams at specialized centers. The option of combining TECAB with PCI in hybrid interventions make it a highly attractive therapeutic option for heart teams and integrated heart centers.

\section{References}

1. Stephenson ER Jr, Sankholkar S, Ducko CT, Damiano RJ Jr. Robotically assisted microsurgery for endoscopic coronary artery bypass grafting. Ann Thorac Surg 1998; 66: 1064-1067.

2. Ducko CT, Stephenson ER Jr, Sankholkar S, Damiano RJ Jr. Robotically-assisted coronary artery bypass surgery: Moving toward a completely endoscopic procedure. Heart Surg Forum 1999; 2: 29-37.

3. Loulmet D, Carpentier A, d'Attellis N, Berrebi A, Cardon C, Ponzio O, et al. Endoscopic coronary artery bypass grafting with the aid of robotic assisted instruments. J Thorac Cardiovasc Surg 1999; 118: 4- 10 .

4. Damiano RJ Jr, Ehrman WJ, Ducko CT, Tabaie HA, Stephenson ER Jr, Kingsley CP, et al. Initial United States clinical trial of robotically assisted endoscopic coronary artery bypass grafting. $J$ Thorac Cardiovasc Surg 2000; 119: $77-82$.

5. Damiano RJ Jr, Ducko CT, Stephenson ER Jr, Lawton JS, Kuenzler RO, Chambers CE. Robotically assisted coronary artery bypass grafting: A prospective single center clinical trial. J Card Surg 2000; 15: $256-265$. 
6. Cichon R, Kappert U, Schneider J, Schramm I, Gulielmos V, Tugtekin SM, et al. Robotic-enhanced arterial revascularization for multivessel coronary artery disease. Ann Thorac Surg 2000; 70: 1060-1062.

7. Kappert U, Cichon R, Schneider J, Gulielmos V, Tugtekin SM, Matschke K, et al. Closed-chest coronary artery surgery on the beating heart with the use of a robotic system. J Thorac Cardiovasc Surg 2000; 120: 809-811.

8. Damiano RJ Jr, Tabaie HA, Mack MJ, Edgerton JR, Mullangi C, Graper WP, et al. Initial prospective multicenter clinical trial of robotically-assisted coronary artery bypass grafting. Ann Thorac Surg 2001; 72: $1263-1268$.

9. Mohr FW, Falk V, Diegeler A, Walther T, Gummert JF, Bucerius J, et al. Computer-enhanced "robotic" cardiac surgery: Experience in 148 patients. J Thorac Cardiovasc Surg 2001; 121: 842-853.

10. Kappert U, Cichon R, Schneider J, Gulielmos V, Ahmadzade T, Nicolai $\mathrm{J}$, et al. Technique of closed chest coronary artery surgery on the beating heart. Eur J Cardiothorac Surg 2001; 20: 765-769.

11. Dogan S, Aybek T, Andressen E, Byhahn C, Mierdl S, Westphal K, et al. Totally endoscopic coronary artery bypass grafting on cardiopulmonary bypass with robotically enhanced telemanipulation: Report of forty-five cases. J Thorac Cardiovasc Surg 2002; 123: 1125 1131.

12. Novick RJ, Fox SA, Kiaii BB, Stitt LW, Rayman R, Kodera K, et al. Analysis of the learning curve in telerobotic, beating heart coronary artery bypass grafting: A 90 patient experience. Ann Thorac Surg 2003; 76: 749-753.

13. Bonatti J, Schachner T, Bernecker O, Chevtchik O, Bonaros N, Ott H, et al. Robotic totally endoscopic coronary artery bypass: Program development and learning curve issues. J Thorac Cardiovasc Surg 2004; 127: 504-510.

14. Bonatti J, Schachner T, Bonaros N, Oehlinger A, Danzmayr M, Rützler $\mathrm{E}$, et al. Ongoing procedure development in robotically assisted totally endoscopic coronary artery bypass grafting (TECAB). Heart Surg Forum 2005; 8: E287-E291.

15. Bonatti J, Schachner T, Bonaros N, Ohlinger A, Danzmayr M, Jonetzko $\mathrm{P}$, et al. Technical challenges in totally endoscopic robotic coronary artery bypass grafting. J Thorac Cardiovasc Surg 2006; 131: 146153.

16. Srivastava S, Gadasalli S, Agusala M, Kolluru R, Naidu J, Shroff M, et al. Use of bilateral internal thoracic arteries in CABG through lateral thoracotomy with robotic assistance in 150 patients. Ann Thorac Surg 2006; 81: 800-806.

17. Argenziano M, Katz M, Bonatti J, Srivastava S, Murphy D, Poirier R, et al. Results of the prospective multicenter trial of robotically assisted totally endoscopic coronary artery bypass grafting. Ann Thorac Surg 2006; 81: 1666-1674.

18. Bonatti J, Schachner T, Bonaros N, Ohlinger A, Rützler E, Feuchtner $\mathrm{G}$, et al. Robotic totally endoscopic double-vessel bypass grafting: A further step toward closed-chest surgical treatment of multivessel coronary artery disease. Heart Surg Forum 2007; 10: E239-E242.

19. de Canniere D, Wimmer-Greinecker G, Cichon R, Gulielmos V, Van Praet F, Seshadri-Kreaden U, et al. Feasibility, safety, and efficacy of totally endoscopic coronary artery bypass grafting: Multicenter European experience. J Thorac Cardiovasc Surg 2007; 134: $710-$ 716.

20. Kappert U, Tugtekin SM, Cichon R, Braun M, Matschke K. Robotic totally endoscopic coronary artery bypass: A word of caution implicated by a five-year follow-up. J Thorac Cardiovasc Surg 2008; 135: 857-862.

21. Bonaros N, Schachner T, Wiedemann D, Oehlinger A, Ruetzler E, Feuchtner G, et al. Quality of life improvement after robotically assisted coronary artery bypass grafting. Cardiology 2009; 114: 59-66.

22. Srivastava S, Gadasalli S, Agusala M, Kolluru R, Barrera R, Quismundo $\mathrm{S}$, et al. Beating heart totally endoscopic coronary artery bypass. Ann Thorac Surg 2010; 89: 1873-1879.

23. Dhawan R, Roberts JD, Wroblewski K, Katz JA, Raman J, Chaney
MA. Multivessel beating heart robotic myocardial revascularization increases morbidity and mortality. J Thorac Cardiovasc Surg 2012; 143: $1056-1061$.

24. Matschke KE, Gummert JF, Demertzis S, Kappert U, Anssar MB, Siclari F, et al. The Cardica C-Port System: Clinical and angiographic evaluation of a new device for automated, compliant distal anastomoses in coronary artery bypass grafting surgery: A multicenter prospective clinical trial. J Thorac Cardiovasc Surg 2005; 130: $1645-1652$.

25. Balkhy HH, Wann LS, Krienbring D, Arnsdorf SE. Integrating coronary anastomotic connectors and robotics toward a totally endoscopic beating heart approach: Review of 120 cases. Ann Thorac Surg 2011; 92: $821-827$.

26. Bonatti J, Lee JD, Bonaros N, Schachner T, Lehr EJ. Robotic totally endoscopic multivessel coronary artery bypass grafting: Procedure development, challenges, results. Innovations (Phila) 2012; 7: 3-8.

27. Rehman A, Garcia J, Deshpande S, Fitzpatrick M, Odonkor P, Zimrin $\mathrm{D}$, et al. Poor left ventricular function is not a contraindication for robotic totally endoscopic coronary artery bypass grafting. Heart Surg Forum 2009; 12: E152-E154.

28. Kon ZN, Lehr E, Odonkor P, Fitzpatrick M, Zimrin D, Griffith B, et al. Is an intraaortic balloon pump a contraindication to robotic totally endoscopic coronary artery bypass? Heart Surg Forum 2010; 13: E399-E401.

29. Rehman A, Garcia J, Deshpande S, Odonkor P, Reicher B, Vesely M, et al. Totally endoscopic coronary artery bypass grafting is feasible in morbidly obese patients. Heart Surg Forum 2009; 12: E134-E136.

30. van Wagenberg FS, Lehr EJ, Rehman A, Bonatti J. Is there a role for robotic totally endoscopic coronary artery bypass in HIV positive patients? Int J Med Robotics Computer Assist Surg 2010; 6: 465467.

31. Lee JD, Vesely MR, Zimrin D, Bonatti J. Advanced hybrid coronary revascularization with robotic totally endoscopic triple bypass surgery and left main percutaneous intervention. J Thorac Cardiovasc Surg 2012 June 17 [Epub ahead of print].

32. Bonatti J, Wehman B, de Biasi AR, Jeudy J, Griffith B, Lehr EJ. Totally endoscopic quadruple coronary artery bypass grafting is feasible using robotic technology. Ann Thorac Surg 2012; 93: e111-e112.

33. Currie ME, Romsa J, Fox SA, Vezina WC, Akincioglu C, Warrington $\mathrm{JC}$, et al. Long-term angiographic follow-up of robotic-assisted coronary artery revascularization. Ann Thorac Surg 2012; 93: 1426-1431.

34. Bonatti J, Schachner T, Bonaros N, Oehlinger A, Wiedemann D, Ruetzler E, et al. Effectiveness and safety of total endoscopic left internal mammary artery bypass graft to the left anterior descending artery. Am J Cardiol 2009; 104: 1684-1688.

35. Kappert U, Cichon R, Tugtekin SM, Schueler S. Closed chest coronary artery bypass on the beating heart. Heart Surg Forum 2001; 4: 89-90.

36. Boyd WD, Rayman R, Desai ND, Menkis AH, Dobkowski W, Ganapathy $\mathrm{S}$, et al. Closed-chest coronary artery bypass grafting on the beating heart with the use of a computer-enhanced surgical robotic system. J Thorac Cardiovasc Surg 2000; 120: 807-809.

37. Loisance DY, Nakashima K, Kirsch M. Computer-assisted coronary surgery: Lessons from an initial experience. Interact Cardiovasc Thorac Surg 2005; 4: 398-401.

38. Srivastava S, Gadasalli S, Agusala M, Kolluru R, Barrera R, Quismundo $\mathrm{S}$, et al. Robotically assisted beating heart totally endoscopic coronary artery bypass (TECAB): Is there a future? Innovations (Phila) 2008; 3: $52-58$

39. Jegaden O, Wautot F, Sassard T, Szymanik I, Shafy A, Lapeze, et al. Is there an optimal minimally invasive technique for left anterior descending coronary artery bypass? J Cardiothorac Surg 2011; 6: 37.

40. Gao C, Yang M, Wu Y, Wang G, Xiao C, Zhao Y, et al. Early and midterm results of totally endoscopic coronary artery bypass grafting on the beating heart. J Thorac Cardiovasc Surg 2011; 142: 843-849. 